\title{
Mobilization of Students at South African Tertiary Institution to Combat Aggravating Factors of HIVIAIDS Transmission: An Action-Research Approach
}

\author{
V. N. Hoho \\ J.G. Kheswa \\ Department of Psychology, University of Fort Hare, Private Bag X1314, Alice, 5700, South Africa \\ Email:vhoho@ufh.ac.za; E-mail: jkheswa@ufh.ac.za
}

\author{
Doi:10.5901/mjss.2014.v5n23p1722
}

\begin{abstract}
The HIVIAIDS has emerged through the last three decades as the most devastating epidemic humankind has ever faced. In the Eastern Cape, HIVIAIDS is rife and the forecast is that HIVIAIDS will have devastating effects among university students unless they change their sexual-behaviour. This research study attempted to highlight the socio-cultural factors which are responsible for HIVIAIDS transmission within the University of Fort Hare with the aim to mobilize and actively involve the students into practicing safe sex. The findings revealed that traditional male circumcision, dry sex, traditional practices, patriarchy, patterns of sexual relationships and drug and alcohol abuse, spread the HIVIAIDS transmission. By means of action research, the collaboration that existed among the professional nurses at the Health Care Center and a team of dedicated Psychology lecturers revealed that the campaigns and workshops which advocate healthy sexual practices could have the propensity to the decline of sexually transmitted infections. The recommendations are that; during welcome-parties for the firstyear students and other social events within the campus, the Health Center must be open to access condoms. Furthermore, since these functions take place on weekends in most cases, field workers should be redeployed to distribute condoms.
\end{abstract}

Keywords: University of Fort Hare, first-year students, culture, condoms, HIVIAIDS.

\section{Introduction}

HIVIAIDS is a widespread throughout the world including in South Africa. To date HIVIAIDS has been declared as one of the fastest growing epidemic in the world with an estimated 40 million people living with HIVIAIDS (WHO, 2007). The Sub-Saharan countries have the highest number of $67 \%$ of people living with HIVIAIDS in the world and women aged 1549 years account for $59 \%$ of all adults living with HIVIAIDS. South Africa is estimated to have more than 5 million people living with HIVIAIDS (UNAIDS, 2008).

In a national antenatal HIV prevalence survey the Department of Health (2009) reported that the prevalence of HIV infections has stabilized nationally around $29 \%$ from 2006. The highest prevalence rate is in the age group 30 to 34 years with a prevalence rate of $40.4 \%$ in 2008 compared to $39.6 \%$ in 2007 (Department of Health 2009). In 2008 the prevalence rate among the 15 to 24 year old women decreased by $0.4 \%$ to $21.7 \%$ as compared to $22.1 \%$ in 2007 with a slight increase of $13.1 \%$ in 2007 to $14.1 \%$ in 2008 among the 15 to 19 year old women (Department of Health, 2009). The results show variations in HIV prevalence between provinces in the age group older than 19 years. These results show a range of $16.1 \%$ in the Western Cape and $45.7 \%$ in KwaZulu- Natal.

The prevalence of HIVIAIDS in all the nine provinces of South Arica showed varying results. The highest HIV prevalence rate was reported in KwaZulu Natal at 39.5\% and the lowest prevalence of $16.9 \%$ was seen in the Western Cape (Department of Health, 2009). The North West and the Free State prevalence rate are reported to be $30.0 \%$ and $30.1 \%$ respectively. The North West province seems to show that results are stabilizing as the 2008 and 2009 report show $30 \%$ and $30.1 \%$ respectively. The Free State province seems to show a decrease of $2.8 \%$, while Gauteng province showed a tendency towards a decrease which is reported to be statistically insignificant. The Eastern Cape shows a slight increase of HIV prevalence from $27.6 \%$ in 2008 to $28.1 \%$ in 2009. Mpumalanga province reported a slight decrease in its results of HIV prevalence from 35.5\% in 2008 to 34.7\% in 2009 (Department of Health, 2009).

The Eastern Cape Province continues to show a slight statistically significant increase in HIV prevalence from 27.6\% in 2008 to $28.1 \%$ in 2009 (Department of Health, 2009). According to the 2009 report the HIV prevalence in the Eastern Cape remains below the national prevalence although that difference was not statistically significant. The HIV prevalence among ante natal care clinic attendees based on age the report shows the economically active group as the 
most affected. The highest prevalence of $38.2 \%$ was seen in the age group 25 to 29 year olds followed by the 30 to 34 year olds whose prevalence was reported at $37 \%$. The prevalence in the 35 to 39 year olds was reported to be at $33.7 \%$ followed by the 20 to 24 year old group which is reported to be at $27.6 \%$. The 40 to 44 year olds were at $25.7 \%$, while those greater than 49 years were found to be at $23.5 \%$. The 45 to 49 year olds the prevalence was at $20.0 \%$ and the 15 to 19 year olds the rate was $12.1 \%$ (Department of Health, 2009)

In the context of high prevalence of HIV in South Africa and a slight increase in some provinces including the Eastern Cape, institutions of higher learning are also bound to be affected. Fort Hare is an institution of higher learning situated in the Eastern Cape. It took part in a national survey conducted by Higher Education in South Africa (HEAIDS) in 2007 to establish the knowledge, attitudes, behaviour and practices that are related to HIVIAIDS and to measure HIV prevalence among students and staff. Young people engage in risky behaviours and practices like substance and alcohol abuse resulting in sometimes having unprotected sex.

In the Eastern Cape region there are four Institutions of higher learning. They are Nelson Mandela Metropolitan University, Rhodes University, Fort Hare University and Walter Sisulu University. The HIV prevalence rate for this region is the highest at $6.4 \%$. The female students showed a higher HIV prevalence of $4.7 \%$ as compared to male students who showed a lower prevalence at $1.5 \%$. The 18 to 19 year old group showed a lower HIV prevalence rate of $0.8 \%$ as compared to 20 to 25 year olds who were at $2.3 \%$. Those who are over 25 years the HIV prevalence rate is reported at a higher prevalence rate of $8.3 \%$. Academic staff HIV prevalence rate was the highest at $3.3 \%$. The female academic prevalence rate is reported to be $2.3 \%$, while males show an increase of $4.0 \%$. The administrative staff is reported at $6.0 \%$ prevalence rate with females showing $5.4 \%$ and males with a slight increase of $7.0 \%$ (HEIDS, 2010).

\section{Fort Hare University Context}

Fort Hare is an institution of higher learning that is situated in the rural areas of the Eastern Cape. These areas include the former homelands of Transkei and Ciskei. It is adjacent to the town of Alice. The university has two other satellite campuses: one located in Bhisho (All Saints Campus) and the East London Campus which is situated in the city center of East London. There are various subgroups of the population namely; the young who are the mostly vulnerable in terms of contracting HIVIAIDS. There are various subgroups of workers that include academics, administrators, technical staff, cleaners and farm workers. It has a population of approximately 8,000 almost IsiXhosa speaking people.

\section{Research Methodology}

This research study employed action research because it does not prove nor test anything. There are no independent and dependent variables, no control and experimental groups and hypotheses that need to be tested (Johnson, 2005). Action Research (AR) is defined as a model of professional development that promotes collaborative inquiry, reflection and dialogue. It refers to a way of learning from and through one's practice by working through a series of reflective stages that facilitates the development (Riel \& Lepori, 2011). Rather than dealing with the theoretical, action research allows the lecturers to address the concerns of the students, ones over which they can exhibit some influence and make a change (e.g. poor - academic performance) (Ferrance, 2000). Furthermore, action research enhances the competence of both the lecturers and students in an immediate situation, using data feedback in a cyclic process (Jarvinen, 2009; Lim, 2007) by enabling the students to select or identify their own areas of development based on collective agreement of priority on what to focus on (Butterfield, 2009). According to Reason (2000), by involving all the stakeholders or participants, action research is aimed at providing skills and knowledge based on practical rather than abstraction. It develops learning organizations- communities of inquiry that are rooted in communities of practice. Furthermore, as action research is underpinned by emancipatory framework and experiential learning, it calls for collaboration.

\subsection{Target Population}

The target population were predominantly students (both males and females), presumably with adequate knowledge about HIVIAIDS who chose not to answer certain questions and that led to significantly skewed results. The campaign was led by the Health Care Center and the New Start continue to support the university to launch these surveillance campaigns of HIVIAIDS to the student body and the academic and administrative personnel. The indication for this was to inform the university management including the financial officers and the university community at large about the trends in the prevalence of the disease. This information also informed health personnel as to how prevention strategies can be adapted for the population of Fort Hare at large including awareness strategies, HIV counseling and testing (HCT) care 
and support and referral for ARV treatment and to make projections for the coming years. The use of these campaigns was also done to determine the number of new HIV infections that have occurred in a given year. With regards to HIVIAIDS surveillance, continuous monitoring of students and personnel at Fort Hare was done through campaigns that were advertised on Radio Forté, intranet, and the cyber space so that the whole community within the institution could participate. Pamphlets for invitations to these campaigns were also distributed. In these campaigns Fort Hare HIVIAIDS surveillance was mostly based on rapid tests, where the volunteers can walk in into the health center and do pre-and post-test counseling. The pre-test counseling was for preparation of testing and the possible outcome and post-test counseling that involved supportive counseling, prevention strategies, medical advice and care (USAID, 2002). Also, blood can be drawn for HIV and Sero-prevalence surveys. These tests were done in the laboratory and reports were sent back to the institution.

\subsection{Ethical considerations}

The ethical measures were taken into consideration during VCT. By informed consent, it means that the participants must be told prior the VCT what the nature and what the procedure will entail by professional nurses from Health Care Center and New Start as suggested by Creswell (2009). Participants were briefed before administering the test and its importance. Confidentiality and anonymity of the participants was guaranteed as well. The research participants' right to privacy was respected. All data obtained was treated in the highest ethical and confidential regard. Research participants were not exposed to undue physical or psychological harm. The researchers ensured that reasonable efforts were made to minimize the discomfort and loss of self-esteem, as suggested by Creswell (2009). It is important to note that the sample from which the blood samples were drawn may not be representative enough. A representative sample means that participants that take part in a research have been randomly selected from the population (Nicholas, 2008). The results obtained in these campaigns were explained with caution. Other factors included lack of biographical information (anonymity) for the test results made it impossible to link blood results with an individual, of which, that is what a good research should base its credibility.

This action research took place in the year 2012 during Valentines' week campaign when 200 pre-test counseled for HIV clients 10 clients tested positive and 6 of them were all females and 4 were males. This shows a high prevalence rate of $6.4 \%$ which is in line with the highest prevalence rate showed by the female students as compared to regional institutions. The male prevalence rate was at $2 \%$ in line with the regional prevalence rate of $1.5 \%$. In some months, for instance of 96 clients pre-test counseled for HIV, three female students tested HIV positive and there were no male students who tested positive. These findings although not an annual statistics showed that females especially in the rural areas of the Eastern Cape are the most affected because of the factors to be explored later.

\subsection{Advantages of the campaign}

The "first things first" campaign is being instituted by HEAIDS. This campaign targets the first year students although other students came in for a testing. The advantage of this campaign is that a number of first year students get to know their status before they are sexually active within the institution. They also get information about preventative measures that are in place and other services that are associated with STI's and sexuality in general. Thereafter it launched a Valentines campaign where New Start comes for a week to the institution for the purposes of testing the students and personnel. They work hand in hand with the University Health Center (i.e. clinic).

Although there was no significant increase in the HIV prevalence estimates in the Eastern Cape Province, women continue to show higher HIV prevalence rate in various regions. This occurs to women who are older than 15 years of age and expected to be economically active or in institutions of higher learning. It was interesting to note that males had the lowest prevalence rate especially at Fort Hare University. These results should be explained with caution because there were no provincial male HIV prevalence rate results for comparison. From the prevalence rate of HIV it is clear that the country as a whole is facing a major crisis with Sub-Saharan countries the most affected. Possible factors that lead to the increase of infections will be explored in section 5 .

\section{Description of how HIV Surveillance Data are Collected and the Advantages of Data Collection Approaches.}

HIVIAIDS has continued to challenge the scientists and health care professionals to date. Since the epidemic began, millions of people have died. The impact of these deaths has been a tragic experience to all families. The Department of Health, (2009) has been doing ante- natal sero-prevalence surveillance since 1990. These surveys indicate an increase 
in the prevalence of HIVIAIDS in all the nine provinces of South Africa. At Fort Hare the surveillance is undertaken weekly, monthly and annually in order to determine the trends and prevalence of HIV. According to Muskat-Gorska, (2008) a lot of people can get infected and the statistics plays a role in giving information about various surveys that are usually done. In surveillance, new technologies that provide unrestrained forms of data collection as well as storage, profiling and transmitting data to a lot of people play an important role. The process of surveillance is problematic for health information because it is personal and private information that is obtained in confidence. The silence and sensitivity around HIVIAIDS has impacted negatively on the progress made in dealing with HIVIAIDS surveillance. Certain communities still treat HIV AIDS as a cultural issue that requires them to treat HIV as a communal disease that must not be talked about.

\section{The Major Factors Causing the Spread of HIVIAIDS}

To understand the context of HIVIAIDS at Fort Hare, a bio- psychosocial model was adopted. This approach looks at biological, psychological and social factors of an individual as part of a larger system (Nicholas, 2008).

\subsection{Poverty}

Poverty refers to the state of deprivation, insufficient physical and economic resources and a low standard of living (Bradshaw, 2002). Fort Hare University is located in The Eastern Cape one of the poorest provinces of South Africa. Children living in poverty face deprivation of many of their rights: survival, health and nutrition, education, protection from harm, exploitation (e.g. sexual abuse) and discrimination (UNICEF, 2005). The students and most of the workers are from this impoverished region. Gilbert and Walker (2002) argue that the subordinate role played by women especially in rural communities as well as ignorance regarding HIVIAIDS makes them vulnerable. This also links with transactional sex which is based on differences in economic power between men and women. Transactional sex takes many forms like commercial sex work, sex for favours, gifts, recreational or travel opportunities.

\subsection{Patriarchal society}

Louw and Edwards (1997) describe patriarchy as a gender prejudice that supported by a cultural system that gives men greater power and privilege than women. The Eastern Cape is a rural patriarchal society where men tend to have more than one sexual partner and the university males are not excluded from this as most of them are from the same communities. Some male students even reported that having more than one partner makes them to be "men" amongst men (HEAIDS 2010). These behaviours especially by older men who have contracted HIV put young girls at risk of contracting HIV because of the belief that engaging in intercourse with a virgin will rid them of HIVIAIDS.

\subsection{Male Circumcision}

Majority of male students studying at Fort Hare are predominantly from villages of Eastern Cape and have traditionally circumcised. Stinson (2008) states that during the operation many young men may contract STIs, HIVIAIDS and other blood-borne infections when the traditional surgeon "ingcibi" rely on using the same assegai without sterilizing it. The mixing of blood may spread HIV infection if among the initiates there is one already infected (White \& Sunter, 2000).

\subsection{Testing the functioning of the penis}

According to Magezi (2007) initiated men (amakrwala) are put under pressure when they come from the initiation school to prove their manhood by having sexual intercourse with women other than their regular sexual partners. This is the way of testing the functioning of their penises and they do this without using condoms, hence the spread of HIV. They also do not want to pass on misfortunes to their valued girlfriends.

\subsection{Male homosexuality}

According to the Center for Disease control and Prevention (2002) men who have sex with men (MSM) are at high risk of contracting HIVIAIDS by $50 \%$ or more, especially those who are the receptors during anal sex. This is a form of sexual behavior that involves a man having anal unprotected sex with another man. Some of these men are bisexual. Evidence 
shows that although people are aware of the HIV and STI's they do not believe that they can contract the infections themselves (WHO, 2007). They infect both male and female partners and spread the infection. During workshop conducted by one of the researchers involved participants in addressing the usage of condoms and how frequent they rely on them. Some participants cited as follows:

\begin{abstract}
"MSM are reluctant to visit the clinics for free condoms as they are aware they might be ostracized should they be seen at the clinics"

"There are lot of bisexuals who hide their sexual identities and even our boyfriends may be gays at night while we have visited our parents and not use condoms when having anal sex"
\end{abstract}

\title{
5.6 Dry sex
}

According to Davis and Tschunin (2006) the dry sex for females is a condition that is the same as irritating the white cells that protect against HIV exposure and wipe the bacteria that usually protects and fight infections and this causes erosion that provides a gateway for HIV virus during sexual intercourse. A study by Mswela (2009), reported that the spread of HIVIAIDS is caused by putting dry agents inside the vagina to absorb the natural vaginal lubricants, which result in friction of the female genitalia which causes excoriation during penetration.

\subsection{Sexual debut}

Young men and women experience the freedom they never thought they would have at university as there is no parental guidance that they have been used to. The HIV Report (2009) points out that a large number of students are likely to have sex for the first time during the period they are at university and that alcohol abuse in particular makes them not to make informed decisions especially about sexual practices. Nicholas (2008) posits that the risks associated with alcohol abuse and unprotected sex are that unplanned and unwanted pregnancy, STD's or HIVIAIDS may occur because when the brain is impaired, one is likely to think irrationally. A better explanation for such behaviour is supported by Alcohol Myopic theory. Theoretically, alcohol myopia restricts intoxicated persons from recognizing or responding to the relevant cues in the environment when faced with whether to have protected or unprotected sex. Alcohol influences one to behave in a more restrained or impulsive manner depending on which cue is more salient or impelling (e.g. the possibility of sexual intercourse in conflict with the possibility of contracting a disease) (Grant \& Mc Donald, 2005). Due to young people's relative inexperience and their need for disinhibition, they may consume large amounts of alcohol based on preconceived alcohol expectancies which may increase their risk of possible HIV infection (Morris \& Albery, 2001).

\subsection{Patterns of sexual relationship}

Students, academic and administrative female workers have multiple sexual partners. Having concurrent sexual partners is the determinant of the spread of HIV. Some students and workers leave their partners at home and establish new relationships when they are at Fort Hare. Crush, Frayne and Grant (2006) report that those who are more mobile and those who have changed residence are at higher risk of contracting the infection and further infecting their regular partners at home. Other concerns which emerged during the workshops were that of concurrent and multiple sexual partners. Both female and male students who attended the workshop cited the following:

"I have 3 sexual partners for one reason. One looks after my looks, the other is responsible for taking me out to Disco and the last one ensures that I have grocery."

"Not all of us are in multiple sexual relationships. But what I have learned since I came to tertiary, only few students have maintained their relationships, but the rest do not last. They change partners. Both genders are the same."

\subsection{Condom use and drug and alcohol abuse}

Various campaigns have been launched to promote the use of condoms as a form of preventing HIV transmission but, they have not been successful. Many people continue to get infected showing some resistance to the use of condoms. The non-use of condoms is mainly influenced by the unequal power relations between men and women. Many studies show that there are people who believe that condoms are unnecessary especially when they see their relationships are stable long term. De Carlo (1999) highlights the fact that some people do not use condoms because they see them as unnatural and compromising the pleasure of intercourse. However, after a role- play showing how HIVIAIDS can be 
spread, even the slides showing the types of STIs (e.g. gonorrhea, syphilis, Hepatitis B and Chlamydia) students who had attended Psychology classes at first year level and those registered for B.Soc Science Extended Programme, became alert and responded differently. Some were quoted saying the following:

"If even a slight STI can lead to infertility, I am going to condomise every time I engage in sex"

"Thanks God I am still safe. I would make sure that I test with my partner if he would want us to have a baby"

From these citations, it is clear that most of the students think that they are invincible and cannot contract HIVIAIDS. Therefore, adults should encourage young people to be faithful to their partners and not expose themselves to illicit drugs and alcohol.

\section{Possible Limitations of the Study}

Given the aim of this research, it is important to note that this research was action-oriented and we were not testing any hypothesis or generating any theory. However attention of the readers is drawn to the fact, considering the demographics of our students, the study was directed at the homogeneous group (i.e. students who share the same language and culture). The limitations associated with these surveillance approaches include the fact that most university students and personnel did not participate in high numbers in these campaigns because of fear of stigma and knowing their status. Our experience was similar to other campaigns due to a low rate in return for test results and a low need to know their status because of fear and feelings of helplessness (Mishra, Rathavuth \& Khan 2008).

\section{Recommendations}

It is clear that quite a number of people are still involved in risky sexual behaviours that put them at high risk for HIV infection. Some members of the university community still lack knowledge and understanding about how HIVI AIDS spread although there is abundance of information and HIV counseling and testing (HCT) services around campus. The recommendations of this research study for other institutions are that:

- The clinic, student counseling unit and Psychology department lecturers or other personnel with the expertise to offer unconditional positive regard to students must do so as in many families, talking about sexual matters with children is still a challenge.

- Sexual behavioural changes must be advocated even by vice-chancellors of the universities to ensure that males refrain from gender-based violence.

- During social events such as beauty contests and welcome parties, there must be peer counselors distributing condoms and some be made available in the bathrooms.

- Finally, to encourage adherence and compliance to ARVs by people living with HIVIAIDS as the pandemic is manageable.

\section{Acknowledgements}

The authors of this research study would like to extend their gratitude to the management of the clinic, students, lecturers and other structures which are actively involved in ensuring that fight against HIVIAIDS, is overcome "SIYAYINQOBA" within the campus.

\section{References}

Bradshaw, J. (2002). "Child Poverty and Child Outcomes". Children and Society, Vol16, 131-140.

Brookmeyer, R. (2010). Measuring the HIVIAIDS Epidemic: Approaches and Challenges. Epidemiologic Reviews, (32):26-37.

Butterfield, J. (2009). Using grounded theory and action research to raise attainment in and enjoyment of reading. Educational Psychology in Practice, Vol 25 (4), 315- 326.

Centers for Disease Control and Prevention. HIVIAIDS Surveillance Report. Atlanta: Centers for Disease Control and Prevention.

Crush, J., Frayne, B. \& Grant, M. (2006). Linking Migration, HIVIAIDS and Urban Food Security in Southern and Eastern Africa. Southern African Migration Project (SAMP). [www.ifpri.org/renewal]

Davis, A. J. \& Tchunin, V. (2006). Essentials of teaching and learning in nursing ethics. Nursing Ethics:

De Carlo, P. (1999). Does sex education work. Internet on-line serial. Available at www.avert.org/sexedu.htm

Department of Health (2009). HIV and Syphilis Sero-Prevalence Survey Report of woman attending Public Antenatal Clinics in the 
Eastern Cape.

Ferrance, E. (2000). Action Research. Themes in Education. Brown University: New England.

Gilbert, L. \& Walker, L. (2002). "Treading the path of least resistance: HIVIAIDS and social inequalities : A South African case study". Science Direct, (54):1-17

HEAIDS (2010). HIV prevalence and related factors. Higher education sector study, South Africa, 2008-2009. Pretoria: Higher Education South Africa.

Jarvinen, P. (2009). On various characteristics of action research. A paper presented in the IRIS32 Conference in Molde, Norway, August 9-12, 2009.

Johnson, A.P. (2005). A Short- Guide to Action Research. (2nd edition). Allyn \& Bacon: Boston.

Lim, P.T.H. (2007). Action -Research For Teachers: A Balanced Model: Proceedings of the Redesigning Pedagogy; Culture, Knowledge and Understanding Conference, Singapore, May 2007.

Louw, D. A. \& Edwards, D.J.A. (1997). Psychology: An introduction for students in Southern Africa. (2nd ed.). Heinemann: Johannesburg. Magezi, V. (2007). HIVIAIDS: Poverty and pastoral care and counseling. Sun Press: Stellenbosch.

Mishra, V. Rathavuth, H., Khan, S. Evaluating HIV Estimates from National POPULATION Based Surveys for Bias Resulting From NonResponse. (DHS Analytical studies no.12). Calverton, MD: Macro International, Inc; 2008

Mswela, M. (2009). Cultural practices and HIV in South Africa: a legal perspective. Potchefstroom Electroniese Regsblad, vol.12 no. 4

Muskat-Gorska, Z. (2008). Privacy, surveillance and HIVIAIDS in the workplace: A South African case study. University of Witwatersrand: Johannesburg.

Nicholas, L. (2008). Introduction to psychology. (2nd ed.). UCT Press: Cape Town.

Stinson, K. (2008). Male circumcision in South Africa: How does it relate to Public Health? Available: http://africanvoices.co.za/culture/ circumcision.htm [2009, November]

Swartz, L., de la Rey, C., Duncan, N. \& Townsend, L. (2011). Psychology: an introduction. (3rd ed.). Oxford University Press: Cape Town. Reason, P. (2001). Learning and change through action research. In J Hendry (Ed.). Creative management. Sage: London

Riel, M., \& Lepori, K. (2011). A- Meta- Analysis of the Outcomes of Action Research. Paper presented at the American Educational Research Association Conference, April 2011. New Orleans.

UNAIDS (2008). Report on the Global AIDS Epidemic.

UNICEF (2005). "Defining child Poverty". http://www.unicef.org/sowc05/english/povertyissue.html. (2 -21 -2005).

USAID (2002). Voluntary counseling and testing, http://www.usaid.org

Whiteside, A. W. \& Sunter, C. (2000). AIDS: The challenge for South Africa. Human \& Rousseau: Cape Town.

WHO, (2007) `Factsheet: Sexually transmitted infections. 